\title{
Identifying the Sustainable Design Elements for the Conservation of Historic Buildings in Malaysia
}

\author{
Yahaya, Shaiful Rizal Che*a, Ahmad, A. Ghafar ${ }^{\mathrm{b}}$ \\ ${ }^{a}$ School of Housing, Building and Planning, Universiti Sains Malaysia, \\ 11800 Minden, Penang, Malaysia \\ ${ }^{\mathrm{b}}$ School of Housing, Building and Planning, Universiti Sains Malaysia, \\ 11800 Minden, Penang, Malaysia \\ *Corresponding Author: shaiful_rzl@yahoo.com
}

\begin{abstract}
The integration of sustainable design elements (SDEs) to the practice of historic building conservation ensures the disused, ineffective or obsolete structures are converted into an economically viable new use which carries both environmental and social benefits whilst retaining its historical values. Although it would heighten its functionality in terms conservation and efficient use of resources, there is an apparent conflict between these two practices as intervention to the historic buildings must adhere to the principles of building conservation which dictates the need to retain the historical values of the building. This poses a challenge to protect the historic values whilst upgrading its usage to suit the contemporary needs and statutory requirement. Currently, there is a lack in the present guidelines that integrates SDEs into the conservation of historic buildings in Malaysia. This paper aims to identify SDEs and practices suitable to be integrated into the guidelines. To achieve this, a documentary review has been conducted by reviewing historic building conservation guidelines from selected countries and few rating tools for assessing building's environmental design and performance. The identified SDE categories are: 1) energy efficiency; 2) water efficiency; 3) materials and resources; 4) indoor environment quality; and 5) sustainable site planning, building and management. From these identified SDEs, qualitative data would be collected to support it. Incorporating these SDEs into the existing guidelines for conservation of historic building would provide guidance to architects, building conservators and other stakeholders in promoting a more sustainable and greener practice of historic building conservation in Malaysia.
\end{abstract}

Keywords: Historic Building Conservation, Energy Conservation, Energy Efficiency, Water Efficiency, Sustainability, Sustainable Design, Sustainable Design Elements

\section{Introduction}

The present global direction of conserving historic building has shifted from merely conserving the tangible cultural heritage for future generation into wider contemporary use to ensure its continuous and sustainable utilisation. This new direction poses great challenge to ensure the conservation of historic buildings meets new functions, comply to the present statutory building regulations, achieve sustainable 
performance while adhere to the principles of building conservation. This paper focuses on identifying Sustainable Design Elements (SDEs) which are relevant to be integrated in the conservation of historic buildings. As conservation guidelines in Malaysia have not clearly incorporate SDEs, this study will be a stepping stone to provide guidance to architects, building conservators and other stakeholders in promoting a more sustainable and greener practice of historic building conservation in Malaysia.

\section{Sustainability in Building Conservation}

Sustainable design is part of the agenda under sustainable development. It relooked into how buildings are designed, constructed and operated to be more responsible to the environment and responsive to the people. The US's General Services Administration, (GSA, 2018) elaborated that sustainable design 'seeks to reduce negative impacts of the environment, and the health and comfort of the building occupants, thereby improving building performance'. Fournier and Zimnicki (2004) underlined sustainable design should achieve efficient use of resources, minimise pollution, provide a healthy and productive indoor environment and economical. It can be deduced the main objective of sustainable design are to minimise the environmental impact of a development and maximise the environmental potential via a thoughtful and sensitive design. Building conservation, as defined by National Heritage Department of Malaysia, is 'the process of maintaining and protecting heritage buildings from being damaged, destroyed, changed or even restored without proper planning and management according to the approved guidelines' (Jabatan Warisan Negara, 2017). According to Malaysia's National Heritage Act 2005, conservation works includes Preservation, Restoration, Rehabilitation, Adaptation or Adaptive Reuse and Maintenance. Conservation of historic building is recognised globally as a sustainable practice by the United Nations (UN) in its Conference on Human Settlement in 1996, through its statement 'conservation, rehabilitation and culturally sensitive adaptive reuse of urban, rural and architectural heritage are also in accordance with the sustainable use of natural and human-made resources' (UN, 1996). The United Nation Economic Programme (UNEP) affirmed that the conservation practice of adaptive reuse to existing buildings is a sustainable practice as it minimises the demolition process that would fill in the landfill (Hong \& Chen, 2017).

The underlying principles of sustainability and building conservation are mutual in a way they are both directed to protect the environment and benefit the society. Integrating SDEs to the practice of historic building conservation would ensures the disused, ineffective or obsolete structures converted into an economically viable new use which carries both environmental and social benefits whilst retaining the heritage values. Building conservation works promotes sustainability as it contributes to environmental performance (Mohamed et. al, 2017; Hong \& Chen, 2017), social responsiveness (Dyson et. al, 2016; Conejos et. al, 2013) and economic viability (Misirlisoy \& Gunce, 2016; Yung \& Chan, 2012). Although integrating SDEs into historic building heightens its functionality in terms of energy efficiency and other green-related benefits, there is an apparent conflict between these two practices as any intervention to the historic buildings must adhere to the principles of building conservation which dictates, amongst others, the need to retain its heritage values. This restriction poses a challenge to protect the heritage values whilst upgrading its usage to suit the contemporary needs. Incorporating these SDEs into the existing guidelines for conservation of historic buildings would provide guidance to architects, building 
conservators and other stakeholders in promoting a more sustainable and greener practice of historic building conservation in Malaysia.

\section{Towards Integrating Sustainable Design and Practices with Conservation of Historic Buildings}

The relationship between building conservation and sustainability has evolved considerably in recent years and now encompasses a broad selection of issues ranging from the authenticity and integrity of preservation to the use of energy in construction via minimum intervention and reversibility (Judson \& Wilkinson, 2012). Rodrigues \& Freire (2017) highlighted that the conservation works must create balance between historical values, implementation of energy efficiency and to satisfy the end user's comfort. With the shift of direction to the present building conservation works, few new terms had emerged that reflect these approaches. Green Adaptive Reuse is a practice that extend the sustainability of adaptive reuse by preserving energy and resources through green design, which emphasise on embedding environmental design and technologies into existing building to upgrade the energy efficiency (Cantell, 2005). Sustainable Adaptation is based on green principles of design when adapting or reusing of historic buildings that emphasised on energy efficiency and eco-friendly materials (Elsorady, 2014) while Constructive Conservation focuses on managing positive change to historic building while accommodating the necessary change to ensure and encourage its continuation of use for present and future generation (English Heritage, 2013).

The SDEs that are installed and applied to new buildings have also been considered for historic buildings, such as energy and water efficiency, reduction of waste, introduction of recycling, specification of low environmental impact materials, effective building operation and facility management (Wilkinson, 2012). These enhancement should be sensitively installed so that it does not cause a conflict with its historic significance. In order to comply with the best practice in historic building conservation, where possible, the measure should be reversible without damaging the original building structure (Goodwin, 2011).

\section{Literature Review}

This conceptual paper is based on the documentary review which identify the SDEs present in the established conservation guidelines from selected countries. In addition, few rating tools for assessing building's environmental design and performance were also reviewed to identify the SDEs that can be incorporated into the conservation of historic buildings. The documents reviewed are the UK's Conservation Principles: Policies and Guidelines - for the Sustainable Management of the Historic Environment, the US's The Secretary of the Interior's Standards for the Treatment of Historic Properties with Guidelines for Preserving, Rehabilitating, Restoring and Reconstructing Historic Buildings and The Secretary of the Interior's Standards for Rehabilitation and Illustrated Guidelines on Sustainability for Rehabilitating Historic Buildings, the Australia's New Uses for Heritage Places: Guidelines for the Adaptation of Historic Buildings and Sites (for New South Wales) and Works Guidelines for Historic Heritage Places (for Tasmania). The sustainable building rating assessment tools reviewed are Malaysia's Green Building Index for Non-Residential Existing 
Building (NREB) and UK's BREEAM UK Refurbishment and Fit-Out Scheme together with a report by Fournier and Zimnicki (2004) titled Integrating Sustainable Design Principles into Adaptive Reuse of Historical Properties.

\section{Existing Historic Building Conservation Guidelines and Sustainable Building Rating Tools.}

The integration of historic conservation works with environmental concerns has now becomes part of the historic building conservation guidelines in many countries. It guides on the installation of new technology or materials to or within the historic fabric, and address the interest in conservation of energy and natural resources and its efficiency. Those guidelines acknowledged, recognised and integrated some SDEs with their principles of conservation to historic buildings. There are four (4) guidelines that have been reviewed as discussed below:

\section{a) Conservation Principles: Policies and Guidelines - for the Sustainable Management of the Historic Environment}

English Heritage (now Historic England), is the UK Government's statutory adviser on the management of the historic environment in England. Their document titled 'Conservation Principles: Policies and Guidelines - for the Sustainable Management of the Historic Environment' (Drury \& McPherson, 2008) was produced to set out a logical approach to making decisions, offering guidance about all aspects of the historic environment and address the challenges of modernising heritage protection by proposing an integrated approach based on sustainable management in England. It takes account on sustainability when introducing intervention to historic building and considers the potential reversibility of changes in order not to prejudice options for the future. In response to the integration of SDEs, Historic England had also produced the guidelines for the installation of renewable energy, improving energy efficiency via sensitive insulation works, complying with public accessibility requirements and sensitive strategy and solution to fire safety.

b) The Secretary of Interior's Standard for Treatment of Historic Properties with Guidelines for Preserving, Rehabilitating, Restoring and Reconstructing of Historic Properties.

In the US, their Secretary of Interior is responsible in establishing professional standards and providing guidance on the preservation of historic properties. Their document titled 'The Secretary of the Interior's Standards for the Treatment of Historic Properties with Guidelines for Preserving, Rehabilitating, Restoring and Reconstructing Historic Buildings' (Grimmer, 2017) was produced to provide the framework for country's preservation programme to historic properties. In addressing the bigger opportunities for the integration of SDEs, another guideline was issued as an extension for rehabilitation works titled 'The Secretary of the Interior's Standards for Rehabilitation \& Illustrated Guidelines on Sustainability for Rehabilitating Historic Buildings' (Grimmer et. al, 2011). This document acknowledges on the numerous treatments and innovation that could upgrade a historic building for more efficient operations. SDEs addressed in this document are early planning for design and actual works, optimisation of window's function and performance for natural lighting and energy-efficiency, water-tightness and insulation for good maintenance and energy 
conservation, optimal operation of HVAC and air-circulation for energy efficient and good indoor environment, installation of renewable energy technologies, design for cool and green roofs for energy conservation, conservation of water, optimisation of natural daylight indoor and sensitive design strategy and solution for compliance with building codes such as accessibility and barrier-free access, impact resisting glazing, security, seismic retrofit, fire-safety.

c) New Uses for Heritage Places - Guidelines for the Adaptation of Historic Buildings and Sites, New South Wales, Australia.

The Heritage Council of the New South Wales (NSW), Australia and the NSW Chapter of Royal Australian Institute of Architects (RAIA) recognised the best way to conserve heritage building is by continuously using it. One of the best methods is to allow the adaptation or adaptive reuse for a new use by responding to the statutory and contemporary requirements while at the same time retain its historic character and fabric. To address the challenges posed by adapting heritage buildings to a new use and explain the principles that guide the adaptation works to minimise conflict, the document ' $\mathrm{New}$ Uses for Heritage Places: Guidelines for the Adaptation of Historic Buildings and Sites' (NSW Dept. of Planning \& RAIA, 2008) was published. The document addresses the sensitive design strategy and solution in order to integrate SDEs, such as compliance with building codes on issues like fire safety, accessibility and barrier-free access, health and safety, security and energy efficiency.

\section{d) Works Guidelines for Historic Heritage Places, Tasmania, Australia.}

The Tasmanian Heritage Council recognised the best way to ensure the heritage places to survive and continue to support its community's identity and memories are through conservation and adaptation. With that affirmation, 'Works Guidelines for Historic Heritage Places' (Tasmanian Heritage Council \& Tasmanian Government, 2015) was produced to provide clarification with regards to the expectation of the Tasmanian Heritage Council and serve as a guidance to help the parties involved to achieve the best possible outcomes when changes are proposed to heritage place. The document provides working guidance on the works to heritage places based on the underlined principles to achieve solutions that adheres to state's sustainable development goals. Apart from the sensitive design for free barrier access, security \& fire safety, SDEs addressed in this document are design solution for new building services, upgrading to energy efficient heating and cooling services, installation of renewable energy equipment, water conservation and installing insulation to building construction components for energy efficiency.

Sustainable design elements and practices from existing sustainable building rating tools for refurbishment works to existing building could also be identified and sensitively adapted for integration with building conservation works, especially on rehabilitation and adaptive reuse to historic building. There are two (2) sustainable building rating tools that have been reviewed as discussed below:

a) Malaysia's GBI (Green Building Index) for Existing Non-Residential Buildings 
As of July 2018, Malaysia does not have a specific conservation guideline that incorporates, if not integrates, sustainable design elements into the practice of conservation to historic buildings. The closest documents available is the 'Green Building Index for Non-Residential Existing Building (NREB)' (GBI, 2018). Green Building Index (GBI) is Malaysia's first comprehensive rating system that evaluate Malaysian buildings on their environmental design and performance. One of the aims of Green Building Index for NREB is to ensure existing buildings are refurbished with SDEs and sustained properly to remain relevant. SDEs assessed in the rating tools are energy efficiency which covers the building's design and performance, indoor environment quality which considers achieving indoor quality standards, sustainable site planning and management that concentrates on the building's management to its external environmental, water efficiency during its occupancy, optimisation \& efficient use of building materials and resources. Although this rating tool does not deal with heritage buildings, most, if not all the SDEs spelled-out, are adaptable for integration with the building conservation works in Malaysia.

\section{b) UK's BREEAM (Building Research Establishment's Environmental Assessment Method) for Refurbishment and Fit-out Works.}

Building Research Establishment's Environmental Assessment Method (BREEAM) is the world's first sustainability rating scheme for built environment that evaluates building on their environmental design and performance. Like Malaysia's GBI, BREEAM has no specific tool that caters for historic properties. The closest document available is 'BREEAM UK Refurbishment and Fit-Out Scheme' (BRE, 2014). SDEs assessed in the rating tools are sustainable management practices through the entire works and post-occupancy, health and wellbeing that consider indoor comfort of building occupants, design and specification for sustainable use of energy, better access to sustainable means of transport for building users, water conservation and efficiency, optimisation and efficient use of building materials, waste management, sensitive treatment on the building's land use and ecology, pollutions generated from the building and other innovation ideas to enhance the sustainability and performance.

In addition to the above, Fournier and Zimnicki (2004) has produced a framework guideline in their report titled 'Integrating Sustainable Design Principles into Adaptive Reuse of Historical Properties'. The report emphasised that the conservation works of adaptive reuse to existing structures must incorporates principles of historic and sustainable design. The SDEs and practices identified for integration with the adaptive reuse and rehabilitation works of historic properties are categorised into six (6). The categories are site related aspects which deals with the management of existing site ecology and environmental impact, optimisation and efficient use of water, energy conservation and efficiency, selective reuse and recycle of building materials, building's indoor environment for the occupant's health and wellbeing and integrating design with effective project management \& implementation.

\section{Identified Potential SDEs and Practices for Conservation of Historic Buildings in Malaysia}

By reviewing the above-mentioned documents, SDEs and practices that have the potential to be adapted for conservation of historic buildings in Malaysia have been identified. These SDEs are grouped in the following five (5) common categories: (1) Sustainable Site Planning, Building and Management; (2) Water Efficiency; (3) Energy 
Efficiency; (4) Material and Resources; and (5) Indoor Environment Quality. Each category consists of several sub-categories as show below:

1.0 Sustainable Site Planning, Building and Management

1.1 Management of Building's Exterior

- Use environmentally sensitive and non-polluting methods and chemicals when maintaining and cleaning the building's exterior, where and when possible,

- Design the external lighting to concentrate only at appropriate areas to avoid unplanned lighting leaving the site and contribute to the night time light pollution to the local sky,

- Target the upward lighting only to specific area to avoid nuisance to the outside public and neighbouring properties,

- Reduce the noise pollution that is generated from the existing or newly specified fixed installation that affecting the neighbouring properties.

1.2 Protection of Historic Landscape Features, Biodiversity and Ecology

- Use organic pesticide or least toxic chemical pesticides or product that consist solely of biodegradable substances, at only targeted locations and only for targeted species, where and when possible,

- Implement a site-sensitive and appropriate sedimentation and erosion control to the existing site,

- Use permeable paving, where appropriate, in order to reduce and delay the discharge of rainfall to public drainage,

- Add rain gardens, if appropriate to the historic building site and settings, in order to reduce or delay the discharge of rainfall to public drainage,

- Identify and mitigate existing site problems and contamination (soil, water and air),

- Enhance and sustain the site's long term biodiversity and ecology, if possible,

- Carry-out landscape works with native or water efficient plants, if appropriate, to enhance the sustainability of historic site.

1.3 Transportation

- Provide priority parking spaces for green (low emitting or fuel efficient) vehicles to encourage use of green vehicles,

- Provide parking capacity not to exceed the minimum numbers required to encourage the usage of public transportation,

- Provide cycle storage and /or facilities to encourage the usage of bicycle to the building.

1.4 Works at Site

- Implement sound environmental management practice to all physical activities at site, ie. erosion and sedimentation control, air pollution prevention, consideration for neighbours etc,

- Project waste management to be practiced where storage facilities and areas must be provided to allow for recycling of project waste and maximise diversion to all the non-hazardous construction and demolition waste from the landfill,

- Maintain a healthy indoor air quality through-out the construction period at the occupied parts of the building, should the works are carried-out on partially occupied building.

1.5 Building Design and Strategy 
- Design to maximise the specification of reused building materials, where and when possible,

- Design to achieve the implementation of universal design principles, where and when possible,

- Design to implement reliable and appropriate security measures and system within the building,

- Design to incorporate appropriate and sensitive measures, where and when possible, to maximise the durability and resilience of building materials from damage due to wear and tear, and from degrading due to environmental and chemical factors.

1.6 Greenery and Roof

- Reducing the Heat Island Effect by adding natural, sustainable and appropriate features at site (plant and other vegetation), where and when possible, to contribute lowering the cooling loads to buildings,

- Avoid paving up to building foundation, if possible, to reduce the heat island effect and damage to the building's foundation,

- Allow native and water-efficient potted plants with appropriate scaled vegetation, placed sensitively (ie. behind the parapet wall) on flat rooftops to minimise the visual impact, to provide shades and contribute to lowering cooling loads at space below,

- Allow appropriate and sensitive installation of secondary roofing materials with high solar reflectivity surface on flat rooftops to minimise the visual impact, to reduce heat gain and lowering the cooling loads at space below.

2.0 Water Efficiency

- Adopt rainwater collection from rooftop or surface runoff for building consumption and irrigation with sensitive and appropriate design and strategy method that minimise impact to heritage significance in order to reduce potable water consumption,

- Adopt recycling of greywater or blackwater, if possible, for building or irrigation use with sensitive and appropriate design strategy that minimise impact to heritage significance to reduce potable water consumption,

- Install water efficient sanitary wares and fittings to reduce potable water consumption, where and when possible (ie. dual flush toilets, self-closing and low-flow aerators to faucets etc),

- Install water metering and leak detection system OR set-up the water monitoring team to monitor and manage the building's water consumption and detect leaking in the water supply system when operational.

\subsection{Energy Efficiency (EE)}

- Analyse and understand the inherent-sustainable features of the building which may contribute to the energy audits exercise in order to identify ways to reduce its energy consumption and more efficient,

- Install insulation materials to the construction system, if possible, with sensitive and appropriate method,

- Retrofit or upgrading the glazing to windows sensitively to minimise the visual impact to the building in order to reduce the solar heat transmission (or $\mathrm{U}$ value) through the window, 
- Specify appropriate materials and colours to improve the thermal response of the building, should the project require such action,

- Upgrade the existing building services systems (HVAC, lighting etc) sensitively, if possible, in order to improve its energy efficiency and performance,

- Allow installation of energy monitoring and sub-metering as Energy Management and Control System OR set-up an energy monitoring team to monitor and control the building's key services of its energy consumption when operational, if possible,

- Allow installation of renewal energy technology (ie. photovoltaic panel, solar heat water panel, mini wind turbine etc) sensitively to heritage fabric and minimising the visual impact to the building and historic setting,

- Designing or improving the internal lighting effectiveness appropriately to reduce energy consumption (ie. install energy efficient light fittings, occupancy auto sensors and dual switches, control and separate and perimeter zones for daylit areas, daylight dimming etc.),

- Specifying energy efficient light fittings and auto-sensors to external lighting to prevent use during daylight hours or when not used,

- Carry-out regular, effective and sensitive maintenance and repair to the building's material, fabric, construction system and services through-out the building's operational period,

- Produce proper operational and maintenance manual on the passive and active systems, historic features and green design strategy and system,

- Provide training for management staff to build awareness and skills for a sustainable building operation.

4.0 Materials and Resources

- Increase demand of building products that incorporates recycled materials in their productions, if possible,

- Use timber or wood product from the environmentally responsible forest management, if possible,

- Implement sustainable purchasing policy, if possible, to ensure materials sourced are in accordance with a sustainable procurement plan (ie. minimising environmental impact etc),

- Provide suitable space for segregation and storage of recyclable waste generated during the building's operation.

5.0 Indoor Environment Quality

- Design the ventilation system sensitively to achieve and maintain a healthy and productive indoor air quality in order to contribute to the comfort and well-being of the occupants,

- Design the ventilation system to be flexible and adaptable to potential future building occupants and functions, if possible,

- Design the ventilation system to reduce the risk of mould growth and its associated detrimental health impact by ensuring positive indoor air pressure is maintained (if mechanically ventilated),

- Prevent possible contamination by tobacco smoke by providing a designated and proper smoking room or prohibit smoking in the building,

- Provide effective ventilation of $\mathrm{CO} 2$ and other harmful emissions,

- Specify sustainable and healthy materials and finishes that contain low Volatile Organic Compound (VOC) and Urea Formaldehyde, 
- Control exposure of building occupants to hazardous materials during building operations should removal of such materials would result in loss of historic significant,

- Develop and implement an Indoor Air Quality (IAQ) Management Plan to effect performing IAQ test according to IAQ code of Malaysia, air purging system annually and annual assessment of comfort of the building's occupants,

- Design to provide thermal comfort system control for individual occupants or specific groups in multi-occupant spaces to promote their productivity, comfort and well-being,

- Implement good level of diffused and natural daylight for building's occupant,

- Ensure daylighting is designed with adequate and proper glare control to reduce discomfort and minimise impact to heritage significance, internally and externally,

- Ensure provision of connectivity with outdoor environment with adequate view to reduce eyestrain for building occupants,

- Ensure the internal lighting is not overdesigned by achieving optimum luminance level for functional task to be performed,

- Install high frequency ballast in fluorescent luminaires to avoid low frequency flicker,

- Maintain the internal noise level at an appropriate level (with appropriate and sensitive use of sound insulation and absorbing materials, if required to do so).

\section{Conclusion}

The practice of conservation of historic buildings is consistent with the sustainable design principles that maximise the utilisation of original building materials, restoration of passive aspects of the original design, preservation of micro-climate and site's ecology and minimisation to the original design. Incorporating conservation and efficient improvement of energy and natural resources via minimal, sensitive and appropriate changes to its original structure and fabric, and improvement of indoor environment quality to enhance health and productivity would ensure that the historic building will perform as a new building and emits lower carbon emission. This research has its limitation, ie. the availability and accessibility to conservation guidelines that are written in English. However, with the above identified SDEs, Jabatan Warisan Negara (JWN) and Jabatan Kerja Raya (JKR) could adapt some, if not all, into their own building conservation guidelines or practices. The adaptation process would have to suit with the principles of building conservation, and reconciles with the contemporary function and the present building codes, by-laws and statutory requirements. Future research could focus on the level of practices suitable for the Malaysian context. Different SDEs could be integrated with different type of conservation works to different listed building categories. This would enhance the sustainable performance of our historic buildings specifically and built environment generally while preserving our rich tangible and cultural heritage. 


\section{References}

BRE Global Limited. (2014). BREEAM UK Refurbishment and Fit-out 2014: Non-domestic buildings. https://www.breeam.com/discover/technical-standards/refurbishment-and-fit-out/ ; visited 13 March 2018.

Cantell, S. F. (2005). The adaptive reuse of historic industrial buildings: regulation barriers, best practices and case studies. The adaptive reuse of historic industrial buildings: Regulation barrier, best practices and case studies. Master Thesis: Virginia Polytechnic Institute and State University, USA, 40.

Conejos, S., Langston, C., \& Smith, J. (2013). AdaptSTAR model: A climate-friendly strategy to promote built environment sustainability. Habitat International, 37, 95-103. doi:10.1016/j.habitatint.2011.12.003

Drury, P., \& McPherson, A. (2008). Conservation principles: policies and guidance for the sustainable management of the historic environment. London: English Heritage.

Dyson, K., Matthews, J., \& Love, P. E. (2016). Critical success factors of adapting heritage buildings: an exploratory study. Built Environment Project and Asset Management, 6(1), 4457. doi:10.1108/bepam-01-2015-0002

Elsorady, D. A. (2014). Assessment of the compatibility of new uses for heritage buildings: The example of Alexandria National Museum, Alexandria, Egypt. Journal of Cultural Heritage, 15(5), 511-521. doi:10.1016/j.culher.2013.10.011

English Heritage. (2013). Constructive Conservation Sustainable Growth for Historic Places.

Fournier, D. F., \& Zimnicki, K. (2004). Integrating sustainable design principles into the adaptive reuse of historical properties. Champaign, IL: US Army Corps of Engineers, Engineer Research and Development Center, Construction Engineering Research Laboratory.

General Services Administration. (2018, March 29). Sustainable Design. Retrieved from https://www.gsa.gov/real-estate/design-construction/designexcellence/sustainability/sustainable-design

Godwin, P. (2011). Building Conservation and Sustainability in the United Kingdom. Procedia Engineering, 20, 12-21. doi:10.1016/j.proeng.2011.11.135

Green Building Index Sdn. Bhd. (2011). GBI for Assessment criteria for Non-Residential Existing Building (NREB). Homepage. http://www.greenbuildingindex.org/; visited 10 March 2018.

Grimmer, A. E. (2017). The Secretary of the Interior's standards for the treatment of historic properties: With guidelines for preserving, rehabilitating, restoring \& reconstructing historic buildings. Government Printing Office.

Grimmer, A. E., Hensley, J.E., Petrella, L., \& Tepper, A.T. (2011). The Secretary of the Interior's Standards for Rehabilitation \& Illustrated Guidelines on Sustainability for Rehabilitating Historic Buildings. Washington, D.C.: U.S. Department of the Interior, National Park Service, Technical Preservation Services.

Hong, Y., \& Chen, F. (2017). Evaluating the adaptive reuse potential of buildings in conservation areas. Facilities, 35(3/4), 202-219. doi:10.1108/f-10-2015-0077

Jabatan Warisan Negara. (2017). Guidelines on Heritage Building Conservation.

Judson, E.P \& Wilkinson, S.J. (2012). Editorial. Historic Environment, 24(2),2-6.

Misırlısoy, D., \& Günçe, K. (2016). Adaptive reuse strategies for heritage buildings: A holistic approach. Sustainable Cities and Society, 26, 91-98. doi:10.1016/j.scs.2016.05.017

Mohamed, R., Boyle, R., Yang, A. Y., \& Tangari, J. (2017). Adaptive reuse: a review and analysis of its relationship to the 3 Es of sustainability. Facilities, 35(3/4), 138-154. doi:10.1108/f-12-2014-0108

New South Wales Department of Planning \& RAIA (2008). New Uses for Heritage Places: Guidelines for the Adaptation of Historic Buildings and Sites. Joint publication of the Heritage Council of New South Wales and the Royal Australian Institute of Architects, Sydney. 
Rodrigues, C. \& Freire, F. (2017). Adaptive reuse of buildings: Eco-efficiency assessment of retrofit strategies for alternative uses of an historic building. Journal of Cleaner Production,157, 94-105. doi:10.1016/j.jclepro.2017.04.104

Tasmanian Heritage Council \& Tasmanian Government. (2015). Works Guidelines for Historic Heritage Places. Tasmanian Government. Retrieved from https://heritage.tas.gov.au/worksand-development/works-guidelines

UN. (1996). Reports of the United Nations Conference on Human Settlements (Habitat II). Istanbul, Turkey.

Wilkinson, S.J. (2012). Back to the Future: Heritage Buildings, Adaptation and Sustainability in the Melbourne Central Business District. Historic Environment, 24(2), 7-13.

Yung, E. H., \& Chan, E. H. (2012). Implementation challenges to the adaptive reuse of heritage buildings: Towards the goals of sustainable, low carbon cities. Habitat International, 36(3), 352-361. doi:10.1016/j.habitatint.2011.11.001 